\title{
Construction of standardized Arabic questionnaires for screening neurological disorders (dementia, stroke, epilepsy, movement disorders, muscle and neuromuscular junction disorders)
}

\author{
This article was published in the following Dove Press journal: \\ Neuropsychiatric Disease and Treatment \\ 30 August 2016 \\ Number of times this article has been viewed
}

\author{
Hamdy N El Tallawy' \\ Wafaa MA Farghaly' \\ Tarek A Rageh' \\ Ahmed O Saleh ${ }^{2}$ \\ Taha AH Mestekawy ${ }^{3}$ \\ Manal MM Darwish ${ }^{4}$ \\ Mohamed A Abd El Hamed' \\ Anwar $M \mathrm{Ali}^{\prime}$ \\ Doaa M Mahmoud' \\ 'Department of Neurology and \\ Psychiatry, Faculty of Medicine, \\ ${ }^{2}$ Psychology Department, Faculty of \\ Education, ${ }^{3}$ Psychology Department, \\ Faculty of Arts, ${ }^{4}$ Public Health \\ Department, Faculty of Medicine, \\ Assiut University, Assiut, Egypt
}

\begin{abstract}
A screening questionnaire is an important tool for early diagnosis of neurological disorders, and for epidemiological research. This screening instrument must be both feasible and valid. It must be accepted by the community and must be sensitive enough. So, the aim of this study was to prepare different Arabic screening questionnaires for screening different neurological disorders. This study was carried out in three stages. During the first stage, construction of separate questionnaires designed for screening the five major neurological disorders: cerebrovascular stroke, dementias, epilepsy, movement disorders, and muscle and neuromuscular disorders were done. Validation of the screening questionnaires was carried out in the second stage. Finally, questionnaire preparation was done in the third stage. Questions with the accepted sensitivity and specificity in each questionnaire formed the refined separate questionnaires.
\end{abstract}

Keywords: screening questionnaires, neurological disorders

\section{Introduction}

Neurological disorders are a major cause of morbidity and mortality all over the world. Of all the people dying every year, around $12 \%$ die of neurological diseases. Stroke is the second leading cause of death after ischemic heart disease worldwide. ${ }^{1-3}$ Disorders that begin in early or midlife, such as seizure disorders, brain injury, multiple sclerosis, and muscular diseases are responsible for a considerable lifetime burden of chronic disability and lost productivity. Disorders that affect the elderly, such as stroke, dementia, and Parkinson's disease, will be of increasingly greater importance as the age of the population increases. ${ }^{4}$

The estimated total population of the Arab world was around 318 million in 2005 and is projected to increase to 480 million in $2030 .^{5}$ The available information on the pattern and frequency of major neurological disorders in Arabic-speaking countries is scanty and limited mainly to hospital-based populations who may not be totally representative of the community. ${ }^{6-8}$ A strategy, which combines population screening using a questionnaire with clinical evaluation of those identified with potential disease by a neurologist, has been designed and found to provide accurate data on the frequency of neurological disease in the community. ${ }^{9-16}$

This study was developed to prepare different Arabic screening questionnaires for screening different neurological disorders, with English translation of the same questionnaire.
Correspondence: Mohamed A Abd El Hamed

Department of Neurology and Psychiatry, Assiut University Hospital, 71526, Said

Marzok Street, Assiut, Egypt

Tel +2088210 2028

$\mathrm{Fax}+20882333327$

Email moh78_abdelhamed@yahoo.com 


\section{Methods}

\section{Strategy of the work}

This was a multistage study (three stages).

\section{The first stage: construction of the questionnaires}

Construction of separate questionnaires (original questionnaires) designed for screening the five major neurological disorders: cerebrovascular stroke, dementias, epilepsy, movement disorders, and muscle and neuromuscular disorders, based on the meticulous reading of different international standardized questionnaires, the World Health Organization (WHO) diagnostic criteria of the disease under the study, ${ }^{15,16}$ the previously standardized questionnaires from former studies, ${ }^{6,10,11}$ as well as on the clinical experience of the staff members of this work. The suggested questionnaires were refereed by 17 expert staff members from different universities, and questions that were agreed upon by $>80 \%$ of the judges were included in the provisional form of the questionnaires.

\section{The second stage: validation of the screening} questionnaires

The validity of the screening questionnaire was carried out by applying it to subjects who were definitely diagnosed with the neurological disorders under the study by expert neurologists according to the $\mathrm{WHO}$ criterion for diagnosis of different neurological disorders to find out the false positive and false negative cases. ${ }^{16}$ Questionnaires were administrated through direct personal interview in neurology clinic in Assiut University Hospital.

The sensitivity, specificity, positive predictive value (PPV) and negative predictive value for each question separately in every questionnaire and the questionnaire as a whole were determined, also construct validity and reliability of each questionnaire were measured.

A pilot study was conducted using the epilepsy questionnaire (epilepsy is the most common disorder among the studied neurological disorders), and after determining the sensitivity, specificity, PPV, and negative predictive value, three questions with unaccepted values were omitted.

Considering the sensitivity, we intended to retain some questions with low sensitivity to avoid missing any case, also sensitivity scores were variable from a studied disorder to another; for example, the questionnaire for muscle and neuromuscular junction disorders screens for three major subtypes of disorders: myopathy, myositis, and myasthenia gravis, and there were different questions for each of them; some having low sensitivity but high specificity.
However, in the dementia questionnaire, for example, we accepted questions with sensitivity scores over $75 \%$ because all the questions diagnose one disease entity, whether the disease is mild, moderate, or severe.

\section{The third stage: the revised questionnaires}

Questions with the accepted scores of sensitivity and specificity were collected to form the final questionnaire for the studied five major neurological disorders.

\section{The diagnostic criteria used}

Diagnoses of different neurological disorders were based on the accepted definition and diagnostic criteria given by the WHO. ${ }^{17,18}$

\section{Patients}

All cases included in the study were patients attending the Assiut University Hospital as outpatients or inpatients, as well as patients from some private clinics.

The number of cases for each neurological disorder under the study was chosen according to the prevalence of the disorder in our locality as follows:

- Stroke: 202 cases

- Epilepsy: 205 cases

- Dementia: 33 cases

- Movement disorders: 40 cases

- Muscle and neuromuscular disorders: 22 cases

Controls were age and sex matched for each questionnaire; they were either healthy relatives or even patients of unrelated illnesses attending the Assiut University Hospital.

\section{Ethics}

Ethical approval for this study was obtained from the Ethics Committee of Assiut University. Each participant provided oral informed consent (children and disabled individuals consented through the responsible person in the family or their caregivers).

\section{Statistical analysis}

Statistics were calculated using SPSS V.16 (SPSS Inc., Chicago, IL, USA) program by three expert staff members in this field; a professor of psychology in the faculty of education, a professor of psychology in the faculty of arts, and a lecturer in the community health department of the faculty of medicine. Data were processed to determine the sensitivity, specificity, PPV and negative predictive value for each question of the five questionnaires as well as the sensitivity and specificity of each individual questionnaire as a whole. 
The methods used for evaluation of the validity and reliability of questionnaires included:

- Translational validity: content validity and face validity

- Construct validity: factor analysis

- Reliability tests: internal consistency (Cronbach's alpha and split-half reliability).

\section{Results}

For validity, factor analysis was performed for each questionnaire, while the internal consistency for each question of the five screening questionnaires, Cronbach's alpha, and split-half reliability was computed to examine the internal consistency of each of the five screening questionnaires as follows:

\section{(A) For dementia questionnaire}

As regard the factor analysis, three factors came off from the 24 original questions with percentage of variation of the initial data $(67.78 \%)$.

The internal consistency of each question is $>0.5$ except for two questions. Cronbach's alpha and split-half reliability showed very high value $(>0.9)$.

\section{(B) For stroke questionnaire}

Two factors came off from the eight original questions with percentage of variation of initial data $(60.208 \%)$. The internal consistency of each question was $>0.5$ except for one question. Cronbach's alpha and split-half reliability showed high value $(>0.7)$.

\section{(C) For epilepsy questionnaire}

Five factors came off from the 12 original questions with percentage of variation of initial data $(71.002 \%)$. The internal consistency of each question is $>0.5$ except for four questions. Cronbach's alpha and split-half reliability showed high value $(>0.6)$.

\section{(D) For movement disorders questionnaire}

One factor came off from the six original questions and explains the bulk of the variability of the original data (47.139\%). Internal consistency of each question is $>0.5$. Cronbach's alpha and split-half reliability showed high value $(>0.7)$.

\section{(E) For muscle and neuromuscular junction disorders}

Three factors came off from the eleven original questions with percentage of variation of initial data $(71.002 \%)$.
Internal consistency of each question is $>0.5$ except for three questions. Cronbach's alpha and split-half reliability showed high value $(>0.7)$.

\section{Dementia screening questionnaire}

After revising the results of sensitivity and specificity of the dementia screening questionnaire, seven questions having sensitivity $<75 \%$ were omitted, which raised the sensitivity of the total questionnaire to $84.2 \%$ while the specificity was $88.2 \%$ (Table 1).

\section{Stroke screening questionnaire}

All the eight questions were kept in the final questionnaire; although most of them had low sensitivity owing to the diversity of presentation of stroke, they were all highly specific, thus the percent of false negative cases was low. So the questionnaire was accepted with a $91.2 \%$ specificity (Table 2 ).

\section{Epilepsy screening questionnaire}

All the 12 questions were kept in the final questionnaire, with sensitivity of the total questionnaire being $74.2 \%$ and specificity $94.3 \%$ (Table 3 ).

\section{Movement disorders screening questionnaire}

All the six questions were kept in the final questionnaire, with sensitivity of the total questionnaire being $64.2 \%$ and specificity $91.5 \%$ (Table 4 ).

\section{Muscle and neuromuscular junction disorders screening questionnaire}

After revising the results of the muscle and neuromuscular junction disorders screening questionnaire, two questions were omitted as they showed very low sensitivity and were less significant in the setting of screening for these disorders (Table 5).

\section{Discussion}

To reduce the burden of brain disorders in the world, epidemiological research should be conducted to monitor the disease burden of brain disorders in developing countries. However, to date, no one knows the true prevalence of neurological disorders in most of the developing countries. One of the major reasons for this is the current lack of a suitable tool for its proper measurement in these settings. ${ }^{1,5}$

This screening instrument must be both feasible and valid. It must be accepted by the community, easily applied by a nonmedical trainee, and brief. It must be sensitive enough so 
Table I The final form questionnaire for screening of dementia

\begin{tabular}{|c|c|c|c|c|}
\hline & Question & Sensitivity (\%) & Specificity (\%) & PPV (\%) \\
\hline \multirow[t]{2}{*}{$\mathrm{I}$} & 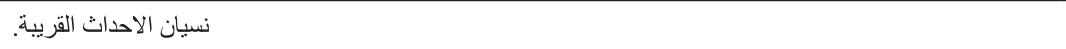 & 87.9 & 64.7 & 70.7 \\
\hline & Forgetfulness of recent events. & & & \\
\hline \multirow[t]{2}{*}{2} & يتعمد ذكر الأحداث البعيدة و خاصة الأحداث المهمة و يكرر ها. & 90.9 & 88.2 & 88.2 \\
\hline & Intend to mention and repeat the remote events especially the important ones. & & & \\
\hline \multirow[t]{2}{*}{3} & 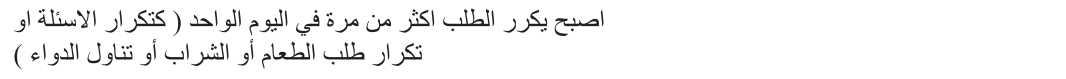 & 81.8 & 85.3 & 84.4 \\
\hline & Repeat orders more than once per day (as repeating questions, asking for food or medicine). & & & \\
\hline \multirow[t]{2}{*}{4} & صعوبة في العثور على الاشياء التي وضعها بنفسه. & 90.9 & 58.8 & 68.2 \\
\hline & Difficulty finding objects he/she placed by himself/herself. & & & \\
\hline \multirow[t]{2}{*}{5} & صعوبة في إيجاد الكلمات الصحيحة عند الكلام. & 87.9 & 91.2 & 90.6 \\
\hline & Difficulty finding the right words while talking. & & & \\
\hline \multirow[t]{2}{*}{6} & يستخدم الكلمات في غير موضعها. & 93.9 & 97.1 & 96.9 \\
\hline & Misuse the words while talking. & & & \\
\hline \multirow[t]{2}{*}{7} & 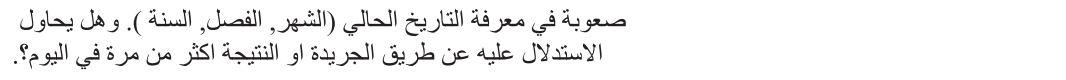 & 78.8 & 94.1 & 92.9 \\
\hline & $\begin{array}{l}\text { Difficulty knowing the current date (month, year, season) and trying to find it through } \\
\text { papers or calendars more than once per day. }\end{array}$ & & & \\
\hline \multirow[t]{2}{*}{8} & اضطراب في الاماكن غير المألوفة لديه أو عند السفر او خارج المنزل و. & 78.8 & 82.3 & 81.3 \\
\hline & Become confused in unfamiliar places, as while travelling or outside the house. & & & \\
\hline \multirow[t]{2}{*}{9} & 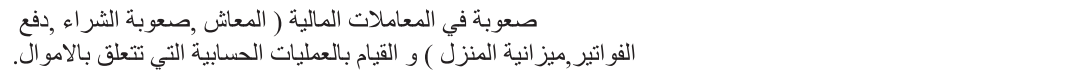 & 78.8 & 91.2 & 89.7 \\
\hline & $\begin{array}{l}\text { Difficulty in handling finances (retirement salary, paying bills, house budget, and doing } \\
\text { mathematical processes related to money). }\end{array}$ & & & \\
\hline \multirow[t]{2}{*}{10} & صعوبة في التنقل بالمو اصلات العامة المعتاد عليها. & 75.8 & 100.0 & 100.0 \\
\hline & Difficulty using their usual public transportations. & & & \\
\hline \multirow[t]{2}{*}{11} & صعوبة في استخدام الادوات ( مثل ريموت كنترول, التيليفون, المنبه). & 84.9 & 100.0 & 100.0 \\
\hline & Difficulty using tools (remote control, mobile, or alarm clock). & & & \\
\hline \multirow[t]{2}{*}{12} & 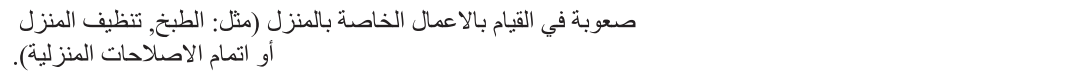 & 90.9 & 100.0 & 100.0 \\
\hline & Difficulty in doing the household activities (cooking, cleaning, or house maintenance). & & & \\
\hline \multirow[t]{2}{*}{13} & صعوبة في القيام بالاعمال المعتادة الخاصة به (كالقراءة والكتاء الطنابه وتناول & 63.6 & 100.0 & 100.0 \\
\hline & $\begin{array}{l}\text { Difficulty in doing their usual activities (reading, writing, eating, dressing, personal hygiene, } \\
\text { and others). }\end{array}$ & & & \\
\hline \multirow[t]{2}{*}{14} & 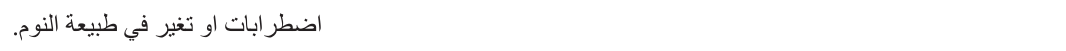 & 87.9 & 88.2 & 87.9 \\
\hline & Change in sleep pattern. & & & \\
\hline \multirow[t]{2}{*}{15} & اصبح اقل اهتماما بالهو ايات او النشاطات الني كان معتادا عليها. & 84.9 & 79.4 & 80.0 \\
\hline & Became less interested in their usual hobbies or activities. & & & \\
\hline \multirow[t]{2}{*}{16} & 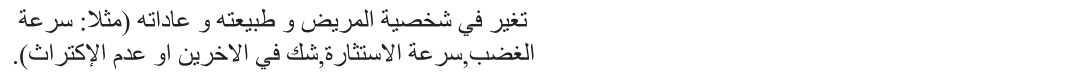 & 87.9 & 88.2 & 87.9 \\
\hline & Personality changes (temperament, delusions, suspicion, or lack of concern). & & & \\
\hline \multirow[t]{2}{*}{17} & صعوبة في الحكم على الاشياء و اتخاذ القرارات أو التخطيط لعمل ما. & 87.9 & 91.2 & 90.6 \\
\hline & Misjudgment and difficulty making decisions or planning for a task. & & & \\
\hline \multicolumn{2}{|c|}{ المورة النهائية للاستبيان } & 84.2 & 88.2 & 88.8 \\
\hline \multicolumn{2}{|c|}{ Final form of the questionnaire $(17 \mathrm{Q})$} & & & \\
\hline
\end{tabular}

Abbreviations: PPV, positive predictive value; $\mathrm{Q}$, questions.

that all participants with neurological disorders are detected for referral to the neurologist, but specific enough so as not to overwhelm these physicians. ${ }^{19}$

One of the first conclusive questionnaires for screening of most neurological disorders was used by El-Tallawy et al, ${ }^{6}$ in which a short Arabic standardized questionnaire was used by three neurologists to pick up suspected cases who were subjected to further clinical and neurological examination. The questionnaire was validated through a pilot study by its application on 100 inpatients from the neurology department 
Table 2 The final form of the questionnaire for screening of stroke

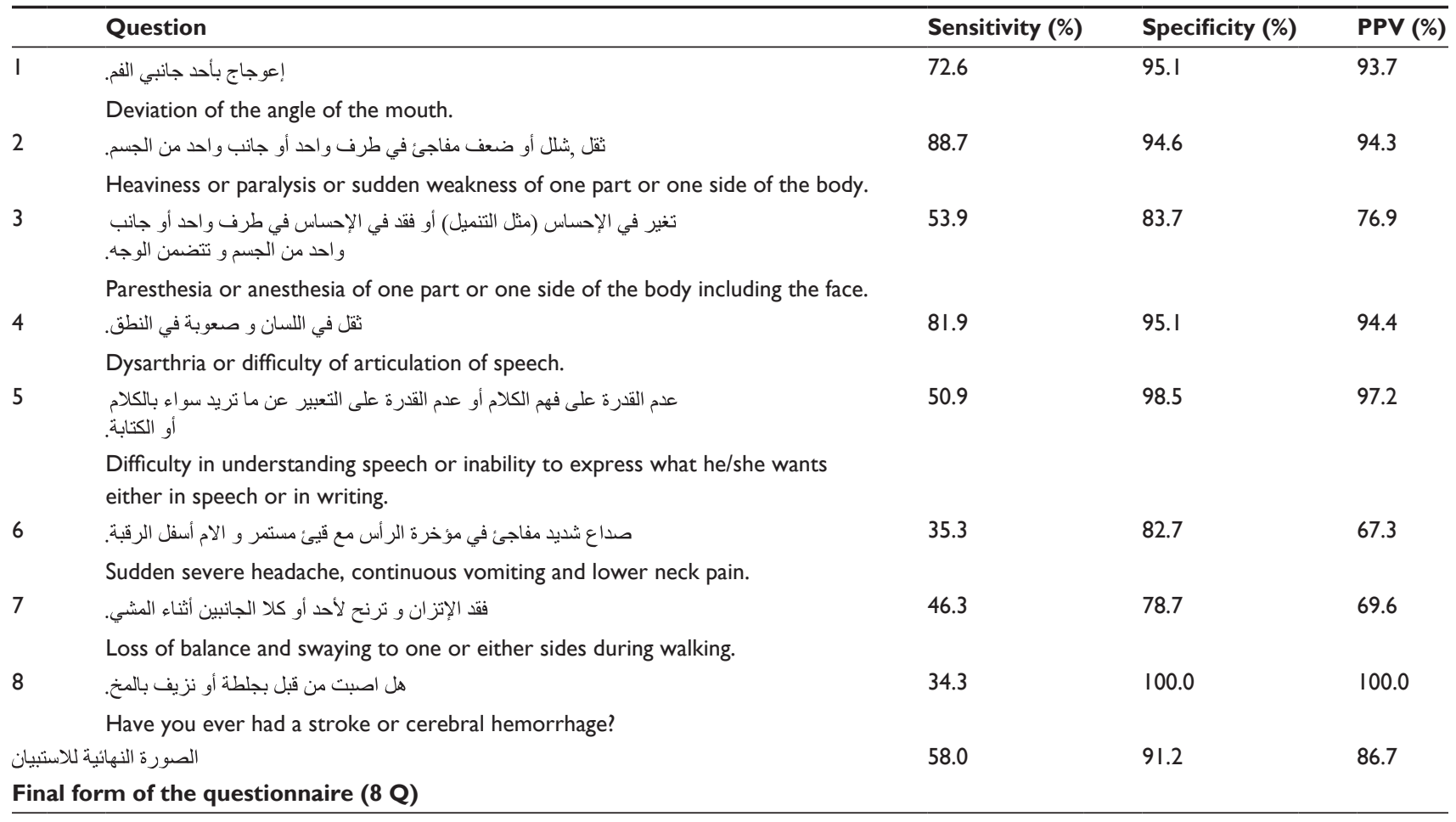

Abbreviations: PPV, positive predictive value; $\mathrm{Q}$, questions.

and 100 patients from the outpatient clinic of neurology in Assiut University Hospital.

A screening questionnaire and its validation are not easily transferable between different populations due to cultural and social influences, and must, in all cases, be piloted and validated for each population.

\section{Dementia}

The questionnaire originally consisted of 24 questions divided into six categories, including memory, language, orientation, visuospatial memory, daily activities, and behavioral or personality changes. The sensitivity of the whole questionnaire was $74.7 \%$ and the specificity was $88.2 \%$. Seven questions having sensitivity $<75 \%$ were omitted from the final version of the questionnaire, raising the sensitivity of the final questionnaire to $84.2 \%$, while the specificity remains unchanged. The PPV of the final questionnaire was $88.8 \%$.

The Early Dementia Questionnaire was developed by Arabi et al in Malaysia, ${ }^{20}$ and compared with the Mini Mental State Examination. Like our study, it had a high sensitivity (79.2\%) but lower specificity (52.7\%) and PPV (23.5\%); this meant that only one-quarter of subjects who test positive will be truly positive.

Maki et $\mathrm{al}^{21}$ in Japan developed the Symptoms of Early Dementia-11 Questionnaire. It was originally a 13 -item questionnaire and compared to the Dementia Rating Scale, assesses memory, daily functioning, social communication, and personality changes. Two items were excluded after analyzing sensitivities and specificities. It had a sensitivity of $76 \%$ and a specificity of $96 \%$.

Sabbagh et $\mathrm{al}^{22}$ in the US developed the Alzheimer's Questionnaire; sensitivity and specificity were found to be high for detecting both Alzheimer's disease (98.55\% and $96 \%$, respectively) and mild cognitive impairment (86.96\% and $94 \%$, respectively).

Similar results were obtained by Storey et a ${ }^{23}$ in Sydney, Australia, who developed and validated a 6-item method for detecting dementia. It assessed multiple cognitive domains, including memory, praxis, language, judgment, drawing, and body orientation. Sensitivity and specificity were $89 \%$ and $98 \%$, respectively.

Also Hatada et al ${ }^{24}$ in Nagasaki developed a self-rating questionnaire for dementia with similar results to our study; the final version had 13 items with sensitivity of $82 \%$ and specificity of $89 \%$.

\section{Stroke}

The questionnaire consist of eight questions; five questions inquire about cerebral stroke (including weakness, dysthesia, dysarthria, dysphasia, and deviation of the mouth), one question inquires about subarachnoid hemorrhage, one question about vertebrobasilar stroke, and the last question about 
Table 3 The final form questionnaire for screening of epilepsy

\begin{tabular}{|c|c|c|c|c|}
\hline & Question & Sensitivity (\%) & Specificity (\%) & PPV (\%) \\
\hline \multirow[t]{2}{*}{$\mathrm{I}$} & اضطر اب الوعي & 94.1 & 95.1 & 95.0 \\
\hline & Loss of consciousness. & & & \\
\hline \multirow[t]{2}{*}{2} & فقد الاتصال أو الاستجابة لمن حوللك & 83.3 & 92.1 & 91.4 \\
\hline & Loss of contact or response to the surroundings. & & & \\
\hline \multirow[t]{2}{*}{3} & تشنجات عصبية أو حركات لا إرادية في أي جزء من الجسم أو الوجه & 90.7 & 97.5 & 97.4 \\
\hline & Convulsions or involuntary movements in any part of the body or the face. & & & \\
\hline \multirow[t]{2}{*}{4} & 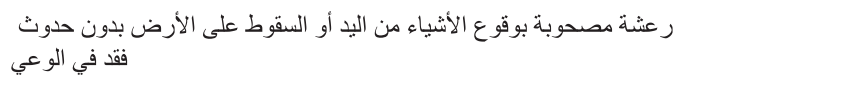 & 28.4 & 95.1 & 85.3 \\
\hline & $\begin{array}{l}\text { Involuntary movement of the hand associated with falling of objects from } \\
\text { the hand or falling on the ground without loss of consciousness. }\end{array}$ & & & \\
\hline \multirow[t]{2}{*}{5} & تتميل بأحد أطر اف الجسم أو أحد جانبي الجسم أو الوجه & 33.8 & 86.6 & 71.9 \\
\hline & Numbness in one part or side of the body or the face. & & & \\
\hline \multirow[t]{2}{*}{6} & 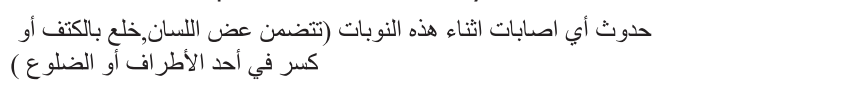 & 68.6 & - & 99.3 \\
\hline & $\begin{array}{l}\text { Occurrence of injuries during the seizure (including tongue biting, } \\
\text { shoulder dislocation, limb, or rib fracture). }\end{array}$ & & & \\
\hline \multirow[t]{2}{*}{7} & إنقلاب كرة العينين إلى الأعلى أو إلى ناحية معينة مع إختفاء سو اد العينين و & 74.5 & - & 99.3 \\
\hline & Up rolling of the eye or its deviation to any side with twisting of the neck. & & & \\
\hline \multirow[t]{2}{*}{8} & خروج ريم أو زبد من الفم & 73.0 & - & 99.3 \\
\hline & Mouth frothing. & & & \\
\hline \multirow[t]{2}{*}{9} & بعد إنتهاء النوبة, هل يعقبها صداع, الام بالجسم, نوم عميق أو نوبات هيجان & 87.3 & - & 98.3 \\
\hline & Occurrence of headache, body aches, or deep sleep following the seizure. & & & \\
\hline \multirow[t]{2}{*}{10} & هل هل حدثت أي من هذه الأعر اض السابقة أثناء النوم & 63.7 & - & 98.5 \\
\hline & Have any of these symptoms occurred during sleep. & & & \\
\hline \multirow[t]{2}{*}{ II } & هل سبق للك عمل رسم مخ & 96.6 & 85.2 & 86.8 \\
\hline & Have you ever had an EEG? & & & \\
\hline \multirow[t]{2}{*}{12} & هل تم تشخيص حالتك بالصر ع أو كهرباء بالمخ & 96.6 & 99.5 & 99.5 \\
\hline & Has your case ever been diagnosed with epilepsy? & & & \\
\hline \multicolumn{2}{|c|}{ الصورة النهائية للاستبيان } & 74.2 & 94.3 & 89.0 \\
\hline \multicolumn{5}{|c|}{ Final form of the questionnaire ( $12 \mathrm{Q})$} \\
\hline
\end{tabular}

Abbreviations: EEG, electroencephalogram; PPV, positive predictive value; Q, questions.

previous history of stroke. The sensitivity of the whole questionnaire was $58 \%$ and the specificity was $91.2 \%$. The PPV of the questionnaire was $86.7 \%$.

O'Mahony et $\mathrm{a}^{25}$ in UK validated a self-completion postal screening questionnaire for assessing lifetime history of stroke, confirmed by a home visit together with multiple sources of case ascertainment. The question "Have you ever had a stroke?" had a sensitivity of $95 \%$ and a specificity of $96 \%$; it disagreed with the results of same question in our study, which had $100 \%$ specificity but $34.3 \%$ sensitivity.

In a study reported by Del Brutto et al, ${ }^{26}$ conducted in Ecuador to evaluate the accuracy of a screening questionnaire for stroke detection in Spanish-speaking communities, was highly sensitive but its PPV was poor. This would cause problems in large-scale studies, as the detection of many false-positives may compromise the viability of the study.
Karanjia et $\mathrm{al}^{27}$ in US developed and validated an easily administered questionnaire and algorithm classifying transient ischemic attacks or strokes, and also their distribution, sensitivity was $87.8 \%$ and specificity was $71.9 \%$.

Abe et $\mathrm{al}^{28}$ in São Paulo, Brazil, validated a questionnaire for evaluating individuals with stroke symptoms. In agreement with this study, it was a stroke symptom questionnaire. The sensitivity was $72.2 \%$, specificity was $94.4 \%$, PPV was $92.9 \%$, and negative predictive value was $77.3 \%$. Limb weakness was the most sensitive symptom, and speech problems were the most specific.

\section{Epilepsy}

Initially the questionnaire consisted of 15 questions (seven main questions and five subquestions in case of a positive response to generalized seizures) and was reduced to 
Table 4 The final form questionnaire for screening of movement disorders

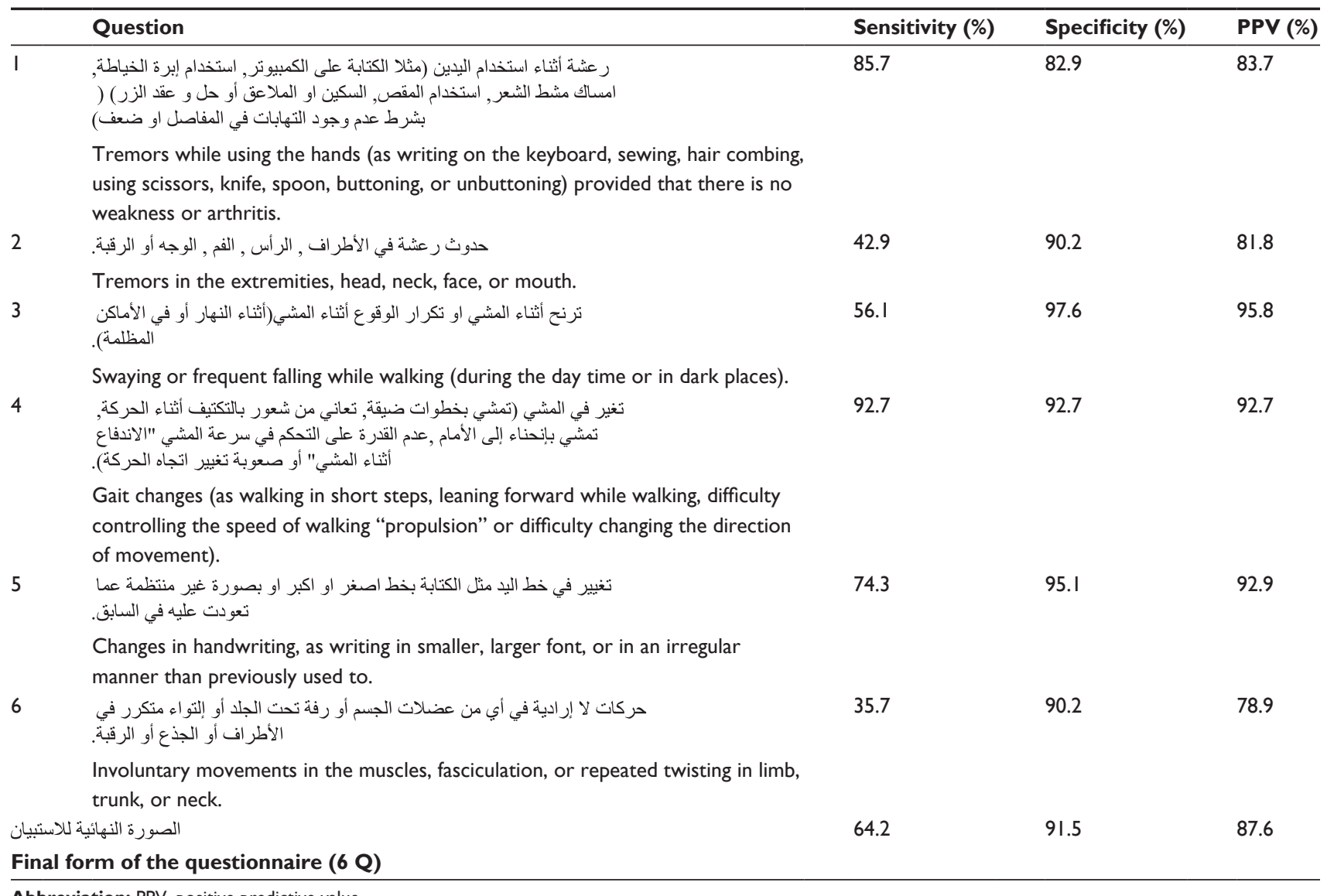

Abbreviation: PPV, positive predictive value.

Table 5 The final form questionnaire for screening of muscle and neuromuscular junction disorders

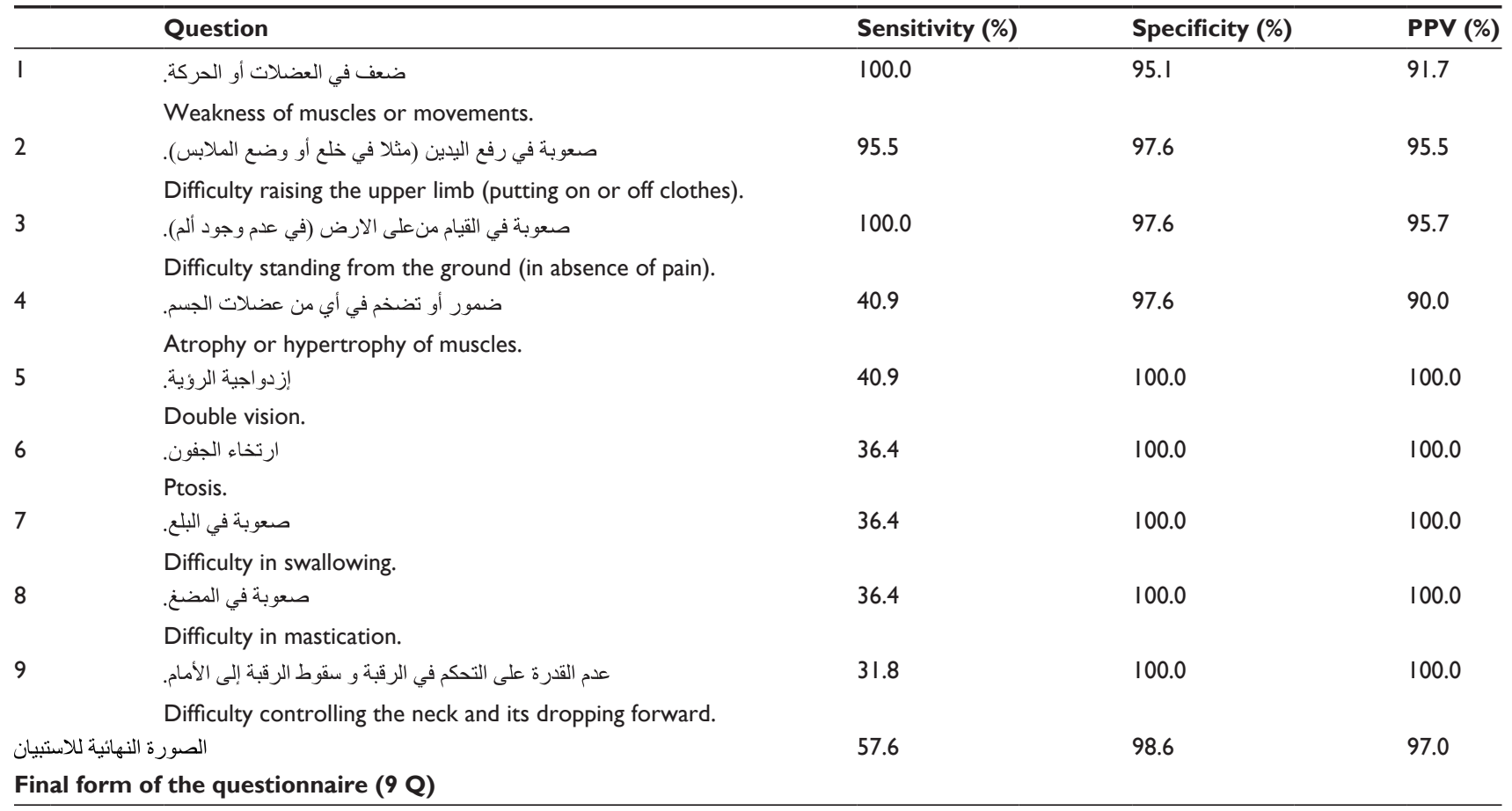

Abbreviation: PPV, positive predictive value. 
12 questions after calculating the sensitivity and specificity in a pilot study. The sensitivity of the whole questionnaire was $74.2 \%$ and the specificity was $94.3 \%$. The PPV of the questionnaire was $89 \%$.

Ottman et $\mathrm{al}^{29}$ in US validated a brief screening instrument for identifying people with epilepsy in epidemiologic or genetic studies. It was a nine question screening instrument for epilepsy and administered by telephone to individuals with medical record documented epilepsy. Sensitivity was $96 \%$ while the PPV was $23 \%$, this study included only patients, while in our study both patients and controls were included, thus had a higher sensitivity score but very low PPP.

In another study by Placencia et $\mathrm{al}^{30}$ in Ecuador, an initial questionnaire consisting of 20 questions was constructed and then validated in a group of healthy subjects and a group of patients with known epileptic seizures. This questionnaire was found to have a sensitivity of $100 \%$ and a specificity of $50.8 \%$. A cluster analysis of the responses rates was undertaken and a set of nine questions, which presented a specificity of $92 \%$ and sensitivity of $98 \%$, were chosen to be used during the survey.

\section{Movement disorders}

This questionnaire originally consisted of six questions, including all symptoms related to movement disorders. The sensitivity of the whole questionnaire was $64.2 \%$ and specificity was $91.5 \%$. The PPV was $87.6 \%$.

Sensitivity and specificity estimates of different screening questionnaires for movement disorder, particularly for parkinsonism, varied widely. Sensitivity estimates were as high as $100 \%$ when questionnaires were tested among previously diagnosed with parkinsonism and included a high number of parkinsonism-specific items, but were as low as $48 \%$ when tested among early cases in a community-based sample. Specificity estimates were lower, ranging from $22 \%$ to $100 \%$. Screening questionnaires can detect symptomatic parkinsonism. However, the performance of these questionnaires varied based on the individual items, study sample, and method of administration. The effectiveness of screening questionnaires in the detection of early or mild parkinsonism was modest. ${ }^{31}$

\section{Muscle and neuromuscular junction disorders}

The questionnaire originally consisted of eleven questions with five subquestions regarding the criteria of the weakness if present, divided into two categories: those about symptoms of muscle disease and those about the symptoms of neuromuscular junction disorders. The sensitivity of the whole questionnaire was $50.4 \%$ and the specificity was $96.5 \%$; two questions were omitted from the final version of the questionnaire, raising the sensitivity of the final questionnaire to $57.6 \%$ and the specificity to $98.6 \%$. The PPV of the final questionnaire was $97 \%$ while the negative predictive value was $82.9 \%$.

Relatively few epidemiological studies have been undertaken with regard to muscle diseases. The true prevalence of neuromuscular disease is usually underestimated because some disorders have few symptoms and are overlooked, or may need specialized investigations to be correctly identified, and the diagnostic criteria are subject to change due to progress in biology and genetics. ${ }^{32}$

El-Tallawy et $\mathrm{al}^{33}$ constructed and validated an Arabic questionnaire for epidemiological studies of muscular disorders in Assiut, Egypt. This study was a cross-sectional study conducted in Assiut Governorate (Upper Egypt) to estimate the prevalence of different types of primary muscular disorder in 1997 using a door-to-door survey. A short questionnaire was designed and the validity was tested in a pilot study on several households before the final form was used in the survey. The sheet was standardized for detection of any case suspected to be a neuromuscular disease.

The constructed and validated Arabic screening questionnaire for cerebrovascular stroke, dementias, epilepsy, movement disorders, muscle, and neuromuscular disorders in this study can be easily, and rapidly administered to pick up any suspicious case, especially during epidemiological research.

\section{Acknowledgment}

This article was presented, which includes work based on a thesis submitted, by the authors HNEl-T, AS, and TR to Assiut University, Egypt (http://www.aun.edu.eg/ thesis files/6633.pdf).

\section{Disclosure}

The authors report no conflicts of interest in this work.

\section{References}

1. Lopez AD, Mathers CD. Measuring the global burden of disease and epidemiological transitions: 2002-2030. Ann Trop Med Parasitol. 2006; 100(5-6):481-499.

2. Bergen DC, Silberberg D. Nervous system disorders: a global epidemic. Arch Neurol. 2002;59(7):1194-1196.

3. WHO. The Global Burden of Disease: 2004 Update. Geneva: World Health Organization; 2008.

4. World Health Organization. Neurological Disorders: Public Health Challenges. Geneva: World Health Organization; 2007. ISBN 924 1563362 (NLM classification: WL 140) ISBN 9789241563369. 
5. World Health organization. Neurological Disorders: Public Health Challenges. 1st ed. Geneva: World Health Organization; 2006.

6. El-Tallawy HN, Farghaly WM, Rageh TA, et al. Epidemiology of major neurological disorders project in A1 Kharga district, New Valley, Egypt. Neuroepidemiology. 2010;35(4):291-297.

7. Al-Rajeh $\mathrm{S}$, Bademosi $\mathrm{O}$, Ismail $\mathrm{H}$, et al. A community survey of neurological disorders in Saudi Arabia: the Thugbah study. Neuroepidemiology. 1993;12(3):164-178.

8. Benamer HT, de SR, Siddiqui KA, Grosset DG. Parkinson's disease in Arabs: a systematic review. Mov Disord. 2008;23(9):1205-1210.

9. Al-Rajeh S, Larbi EB, Bademosi O, Awada A, Ismail H, al-Freihi H. Stroke in a tertiary hospital in Saudi Arabia: a study of 372 cases. J Neurol Sci. 1991;102(1):112-118.

10. Bower JH, Mwendo E, Walker R, Maro V, Enquosellasie F, Ali A. Validity of a screening instrument for neurologic disability in resourcepoor African communities. J Neurol Sci. 2012;320(1-2):52-55.

11. Dewhurst F, Dewhurst MJ, Orega G, et al. Neurological disorder screening in the elderly in low-income countries. J Neurol. 2012; 259(10):2189-2197.

12. Chandra V, Pandav R, Laxminarayan R, et al. Neurological disorders. In: Jamison DT, Breman JG, Measham AR, et al, editors. Disease Control Priorities in Developing Countries. 2nd ed. Washington, DC World Bank; 2006. Chapter 32.

13. Mathers, CD, Lopez A, Stein C, Doris MF, Rao C, Inoue M. Deaths and Disease Burden by Cause: Global Burden of Disease Estimates for 2001 by World Bank Country Groups. Washington, DC: World Bank; 2005.

14. Schoenberg BS. Clinical neuroepidemiology in developing countries: neurology with few neurologists. Neuroepidemiology. 1982;1(3): 137-142.

15. World Health Organization. Research Protocol for Measuring the Prevalence of Neurological Disorders in Developing Countries. Neurosciences Program, Geneva: World Health Organization; 1981.

16. World Health Organization. International Statistical Classification of Disease and Related Health Problems. 10th revision, vol 2. Geneva: World Health Organization; 2012.

17. Bharucha NE, Bharucha EP, Dastur HD, Schoenberg BS. Pilot survey of the prevalence of neurologic disorders in the Parsi community of Bombay. Am J Prev Med. 1987;3(5):293-299.

18. Das SK, Sanyal K. Neuroepidemiology of major neurological disorders in rural Bengal. Neurol India. 1996;44(2):47-58.

19. Meneghini F, Rocca WA, Anderson DW, et al. Validating screening instruments for neuroepidemiologic surveys: experience in Sicily. J Clin Epidemiol. 1992;45(4):319-331.
20. Arabi Z, Aziz NA, Abdul Aziz AF, Razali R, Wan Puteh SE. Early Dementia Questionnaire (EDQ): a new screening instrument for early dementia in primary care practice. BMC Fam Pract. 2013;14:49.

21. Maki Y, Yamaguchi T, Yamaguchi H. Symptoms of Early Dementia-11 Questionnaire (SED-11Q): a brief informant-operated screening for dementia. Dement Geriatr Cogn Dis Extra. 2013;3(1):131-142.

22. Sabbagh MN, Malek-Ahmadi M, Kataria R, et al. The Alzheimer's Questionnaire: a proof of concept study for a new informant-based dementia assessment. J Alzheimers Dis. 2010;22(3):1015-1021.

23. Storey JE, Rowland JT, Basic D, Conforti DA, Dickson HG. The Rowland Universal Dementia Assessment Scale (RUDAS): a multicultural cognitive assessment scale. Int Psychogeriatr. 2004;16(1): 13-31.

24. Hatada K, Okazaki Y, Uchino J, Yoshitake K, Takada K, Nakane Y. The development of a self-rating questionnaire for screening dementia citation. Acta medica Nagasakiensia. 1997;42(3-4):34-38.

25. O'Mahony PG, Thomson RG, Dobson R, Rodgers H, James OF. The prevalence of stroke and associated disability. J Public Health Med. 1999;21(2):166-171.

26. Del Brutto OH, Idrovo L, Mosquera A, et al. Stroke in rural Ecuador: a three-phase, door-to-door survey. Neurology. 2004;63(10): 1974-1975.

27. Karanjia PN, Nelson JJ, Lefkowitz DS, et al. Validation of the ACAS TIA/stroke algorithm. Neurology. 1997;48(2):346-351.

28. Abe IM, Lotufo PA, Goulart AC, Benseñor IM. Stroke prevalence in a poor neighbourhood of São Paulo, Brazil: applying a stroke symptom questionnaire. Int J Stroke. 2011;6(1):33-39.

29. Ottman R, Barker-Cummings C, Leibson CL, Vasoli VM, Hauser WA, Buchhalter JR. Validation of a brief screening instrument for the ascertainment of epilepsy. Epilepsia. 2010;51(2):191-197.

30. Placencia M, Shorvon SD, Paredes V, et al. Epileptic seizures in an Andean region of Ecuador: incidence and prevalence and regional variation. Brain. 1992;115(Pt 3):771-782.

31. Dahodwala N, Siderowf A, Baumgarten M, Abrams A, Karlawish J. Screening questionnaires for parkinsonism: a systematic review. Parkinsonism Relat Disord. 2012;18(3):216-224.

32. Gautier FM, Fardeau M. Socioeconomic aspect of neuromuscular diseases. In: Engel AG, Franzini-Armstrong C. editors. Myology. 2nd ed. New York: McGraw-Hill; 1995: 739-745.

33. El-Tallawy HN, Khedr EM, Qayed MH, Helliwell TR, Kamel NF. Epidemiological study of muscular disorders in Assiut, Egypt. Neuroepidemiology. 2005;25(4):205-211.
Neuropsychiatric Disease and Treatment

\section{Publish your work in this journal}

Neuropsychiatric Disease and Treatment is an international, peerreviewed journal of clinical therapeutics and pharmacology focusing on concise rapid reporting of clinical or pre-clinical studies on a range of neuropsychiatric and neurological disorders. This journa is indexed on PubMed Central, the 'PsycINFO' database and CAS,

\section{Dovepress}

and is the official journal of The International Neuropsychiatric Association (INA). The manuscript management system is completely online and includes a very quick and fair peer-review system, which is all easy to use. Visit http://www.dovepress.com/testimonials.php to read real quotes from published authors. 